\title{
DETEKSI OBYEK MENGGUNAKAN TEKNIK MULTIRESOLUSI UNTUK CITRA TUMOR TUBERCOLUSE
}

\author{
Indra Riyanto ${ }^{1}$, Wihartini ${ }^{1}$ \\ ${ }^{1}$ Fakultas Teknik Universitas Budi Luhur \\ indra@bl.ac.id, wihartini@bl.ac.id
}

ABSTRAK

Segmentasi adalah salah satu cara diagnostik yang penting untuk menemukan penyebaran tumor. Pada penelitian ini digunakan citra paru-paru yang sudah terinfeksi tumor tubercoluse. Kemajuan teknologi di bidang pengolahan citra sudah sangat maju, sehingga dapat mendukung dalam penganalisaan tumor. Salah satunya adalah deteksi obyek menggunakan teknik multiresolusi. Sasaran dari penelitian ini adalah deteksi obyek menggunakan metode teknik multiresolusi wavelet a trous dan selanjutnya dilakukan proses segmemtasi untuk mengidentifikasi penyebaran tumor pada skala yang berbeda. Untuk mendapatkan pengamatan yang lebih detail dapat dilakukan teknik threshold sehingga terlihat dengan jelas area penyebarannya.

Kata Kunci : Teknik multiresolusi, segmentasi dan threshold

\section{PENDAHULUAN}

Kemajuan Teknologi yang sangat pesat dewasa ini sangat mendukung kegiatan dibidang kedokteran. Meskipun dukungan teknologi ini sangat terasa manfaatnya tapi diagnosis tumor atau kanker hingga kini masih berdasarkan tanggapan subyektif ahli patologi anatomik. Maka tidak mengherankan bila dari sepotong jaringan yang dilihat oleh beberapa ahli patologi anatomik akan terdapat beberapa pendapat yang berbedabeda. Pada beberapa keadaan diagnosis morfologik suatu tumor sangat sukar karena sesuatu sebab. Maka sangat penting agar para ahli klinik melakukan biopsi yang representatif yaitu dengan dukungan pengolahan citra.

Penelitian ini akan menggunakan teknik multiresolusi wavelet à Trous, Dengan teknik multiresolusi dapat diperoleh informasi yang lebih banyak. Guna mencapai maksud tersebut transformasi à Troust akan menguraikan citra asli $\mathrm{c}_{0}$ kedalam citra approksimasi atau disebut juga dengan produk skalar $c_{j}$ ditambah citra-citra detil $\mathrm{w}_{\mathrm{i}}$ dengan $\mathrm{i}=1,2, . . \mathrm{j}$, dimana $\mathrm{j}$ adalah skala tertinggi.

Deteksi Obyek Menggunakan Teknik.... (Indra Riyanto)
Karena untuk melakukan deteksi obyek dari satu set citra detil perlu persyaratan yaitu ukuran citra harus sama yang berarti bahwa dalam transformasinya ukuran citra tidak boleh berubah. Algoritma transformasi wavelet á Troust merupakan metoda yang tepat untuk digunakan dalam proses deteksi obyek. Selain itu sifat transformasi yang stasioner akan menghasilkan redundansi antara citra-citra detil pada masing-masing skala.

$\mathrm{c}_{\mathrm{o}}=\mathrm{c}_{\mathrm{j}}+\mathrm{w}_{1}+\mathrm{w}_{2}+\ldots \ldots+\mathrm{w}_{\mathrm{j}}$

dan

$$
w_{j}=c_{j-1}-c_{j}
$$

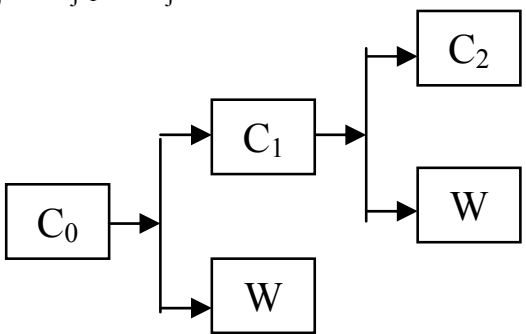

Gambar 1. Transformasi Wavelet à Trous sampai Level 2

Selanjutnya dilakukan proses unsupervised classification. atau segmentasi. Untuk mendapatkan detail area penyebaran 
tumor dari citra digunakan teknik thresholding

\section{DATA DAN METODOLOGI}

Metode penelitian yang digunakan adalah metode pengenalan pola dengan menggunakan pengolahan citra digital (digital image processing ) yaitu menggunakan teknik multiresolusi wavelet à trous dan segmentasi menggunakan unsupervised classification,

Penelitian ini akan membahas tentang identifikasi obyek citra tumor tubercoluse seperti terlihat pada Gambar 1. dimana obyek penelitian adalah hasil biopsi yang akan diubah ke bentuk citra digital sehingga datanya bisa diolah.

Gambar 2. memperlihatkan citra tumor tuberculosis yang akan dianalisis menggunakan teknik multiresolusi dan klasifikasi. Bulatan hitam yang terlihat pada Gambar 2 adalah tumor tubercoluse.

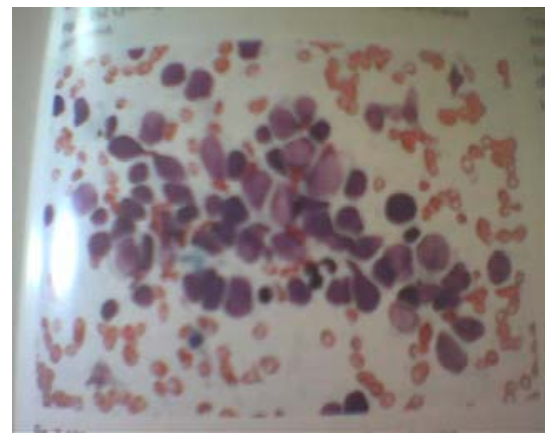

Gambar 2. Citra Asli Tumor Tbc

\section{WAVELET Ă TROUS}

\subsection{Transformasi $\overline{\mathbf{A}}$ Trous}

Algoritma à trous adalah salah satu algoritma untuk identifikasi obyek pada skala yang berbeda yaitu menggunakan transformasi wavelet yang versifat statis. Suatu transformasi wavelet untuk data diskrit dapat diperoleh melalui versi yang dikenal sebagai algoritma à trous (yang artinya: dengan lubang, atau "hole") (Holschneider et al., 1989, Shensa, 1992) [11]. Algoritma à trous adalah "non-dyadic resolution". Ini adalah transformasi stasionair, karena tidak dilakukan proses pengerutan citra. Transformasi wavelet suatu citra yang menggunakan algoritma seperti à trous dalam 1-dimensi akan menghasilkan satu set $w_{j}$ pada skala $j=1,2 . . n s, n s=$ skala tertinggi, yang berisi informasi detail dan satu produk skalar $c_{j}$ berisi informasi citra. Baik $w_{j}$ maupun $c_{j}$, keduanya mempunyai jumlah pixel yang sama dengan citra aslinya.

$c_{0}(k)=c_{n s}(k)+\sum_{j=1}^{\mathrm{ns}} w_{j}(k)$

dimana $n s=$ banyak skala,

Dengan memisalkan bahwa sample data $\left\{c_{0}(k)\right\}$ adalah produk skalar $f(x)$ di pixel $k$ dengan fungsi penyekalaan $\phi(x)$ di translasi ke

$\phi(x-k): c_{0}(k)=<f(x), \varphi(x-k>$

Maka produk skalar pada skala $j$, adalah sebagai berikut:

$c_{j}(k)=\frac{1}{2^{j}}\left\langle f(x), \varphi\left(\frac{x-k}{2^{j}}\right)\right\rangle$

Jika persamaan dilasi untuk $\varphi(x)$ adalah $\frac{1}{2} \varphi\left(\frac{x}{2}\right)=\sum_{n} h(n) \phi(x-n)$

Dari uraian diatas, secara umum persamaan produk skalar akan diperoleh sebagai berikut

$c_{j+1}(k)=\sum_{n} h(n) c_{j}\left(k+2^{j} n\right)$

Fungsi spline, bagian dari polynomial, mempunyai sifat approksimasi data yang sangat mudah dikenal (Strang dan Nguyen, 1996). Kubik sentral B-spline $B_{3}(x)$ akan digunakan pada penelitian ini, yaitu :

$$
\begin{aligned}
h(n)= & \{1 / 16 ; 1 / 4 ; 3 / 8 ; 1 / 4 ; 1 / 16\} ; \\
& (-2 \leq \mathrm{n} \leq 2)
\end{aligned}
$$

dan hasil wavelet dari perbedaan antara dua approksimasi berikutnya adalah : $w_{j}(k)=c_{j-1}(k)-c_{j}(k)$

Rumus (9) menyatakan korelasi dari citra detail $w_{j-1}$ dengan $w_{j}$ tersebut dapat dibuktikan secara analitis melalui uraian dibawah ini dengan menggunakan fungsi segitiga $\phi$,

Terlihat dari persamaan (5), bagaimana produk skalar dapat diperoleh dari 
skala rendah $j=0$ sampai skala tertinggi $n s$, yaitu skala tertinggi yang diinginkan.

$j=0$ :

$c_{1}(0)=h(-2) c_{0}(-2)+h(-1) c_{0}(-1)+h(0)$
$c_{0}(0)+h(1) c_{0}(1)+h(2) c_{0}(2)$
$c_{1}(1)=h(-2) c_{0}(-1)+h(-1) c_{0}(0)+h(0)$
$c_{0}(1)+h(1) c_{0}(2)+h(2) c_{0}(3)$

$c_{1}(k)=h(-2) c_{0}(k-2)+h(-1) c_{0}(k-1)+h(0) c_{0}(k-$ $0)+h(1) c_{0}(k+1)+h(2) c_{0}(k+2)$

$j=1$ :

$c_{2}(0)=h(-2) c_{1}(-4)+h(-1) c_{1}(-2)+h(0)$

$c_{1}(0)+h(1) c_{1}(2)+h(2) c_{1}(4)$

$c_{2}(1)=h(-2) c_{1}(-3)+h(-1) c_{1}(-1)+h(0)$

$c_{1}(1)+h(1) c_{1}(3)+h(2) c_{1}(5)$

$c_{2}(k)=h(-2) c_{1}(k-2)+h(-1) c_{1}(k-1)+h(0) c_{1}(k-$ $0)+h(1) c_{1}(k+1)+h(2) c_{1}(k+2)$

dimana $\mathrm{k}$ adalah lokasi piksel dalam satu dimensi dari 0 sd 255.

Jika harga $\left(k+2^{j} n\right)$ dari $c_{j}\left(k+2^{j} n\right)$ bernilai negatif, maka aturan "mirror" akan digunakan, yaitu :

$c(k-n)=c(k+n)$

Gambar 2, mempererlihatkan bahwa harga pixel ke- $k$ pada skala $(j+1)$ dipengaruhi oleh 5 harga dari pixel ke- $\left(k+2^{j} n\right)$. Hal ini menyebabkan obyek yang berbentuk sungai, akan kelihatan melebar pada skala yang lebih tinggi. Sedang obyek yang merupakan gerombolan besar atau kecil, akan berkurang atau membesar volumenya atau bahkan hilang pada skala yang lebih tinggi

$\mathrm{c}_{0}$

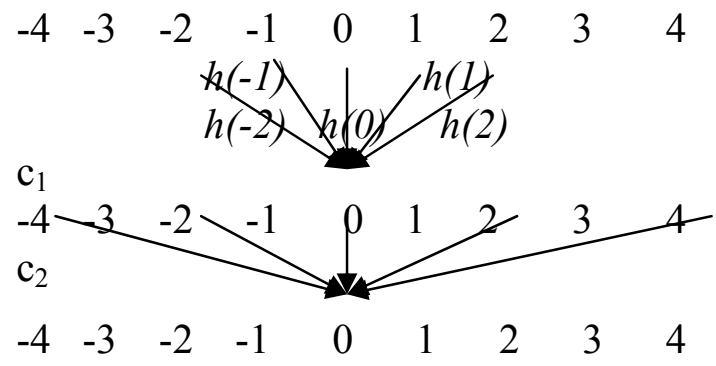

Gambar 3. Lintasan Pproduk Skalar dari $c_{0}$ ke $c_{1}$, dan $c_{1}$ ke $c_{2}$

Selanjutnya rekonstruksi citra dapat dilakukan dengan menggunakan formula:

$$
c_{0}(k)=c_{n s}+\sum_{j=1}^{n s} w_{j}(k)
$$

Transformasi wavelet à trous dengan skala $(j)=3$, hasilnya ditunjukkan pada Gambar 4. Dari gambar terlihat satu set citra detail, yaitu $w_{1}, w_{2}$ dan $w_{3}$ yang diperoleh dari perbedaan $c_{j-1}-c_{j}$ dimana $j=1 . .3$, dan satu citra aproksimasi dari skala tertinggi $c_{3}$. Dari citra detail terlihat bahwa struktur obyek dengan frekuensi rendah seperti sungai terlihat lebih jelas pada citra detail skala tinggi.
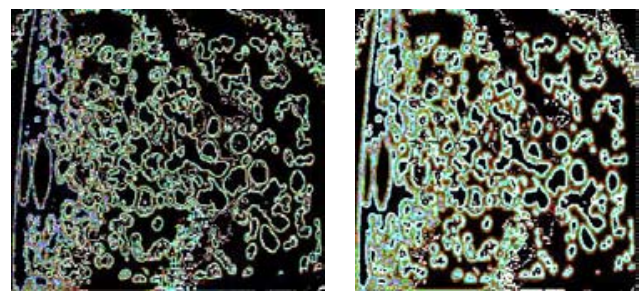

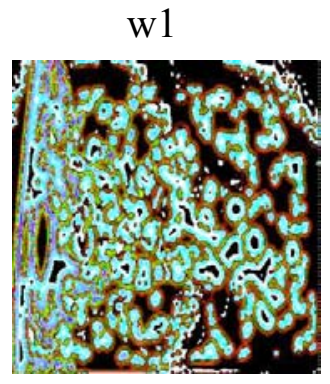

w3

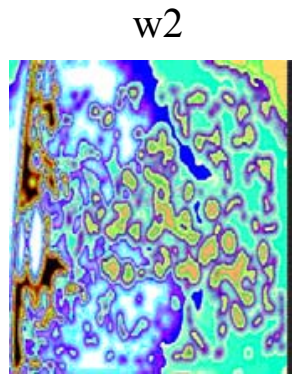

c3
Gambar 4. Transformasi Wavelet à trous

\subsection{Segmentasi Citra}

Proses segmentasi pada penelitian ini adalah unsupervised classification yang dilakukan setelah teansformasi wavelet à trous. Transformasi dilakukan yaitu untuk melihat obyek-obyek pada skala yang berbeda. Hal ini dapat dilihat pada Tabel 1 yang menunjukkan nilai pixel per klas dari citra c0. Dari tabel 1 terlihat bahwa nilai pixel klas 2 dan klas3 sama sehingga menunjukkan hanya ada 2 klas saja pada citra asli. Tabel 2, Tabel 3 dan Tabel 4 yang menunjukkan nilai pixel citra $\mathrm{c} 1, \mathrm{c} 2$ dan $\mathrm{c} 3$ dari hasil transformasi menunjukkan terjadi pengelompokan nilai menjadi 3 klas Pada skala yang berbeda yaitu skala 1 , skala 2 dan 
skala 3 dimana nilai pixel terlihat pada Tabel 2, Tabel 3 dan Tabel 4 apabila di amati terlihat terjadi pelebaran daerah cakupan pada setiap klasnya. Keadaan ini bisa di asumsikan seperti melihat obyek menggunakan mikroskop, makin dekat maka obyek akan terlihat makin besar.

Tabel 1. Nilai Pixel Hasil Klasifikasi c0

\begin{tabular}{|c|c|}
\hline Klas & Nilai pixel \\
\hline 1 & $0-123$ \\
2 & $160-255$ \\
3 & $160-255$ \\
\hline
\end{tabular}

Tabel 2. Nilai Pixel Hasil Klasifikasi c1

\begin{tabular}{|c|c|}
\hline Klas & Nilai pixel \\
\hline 1 & $19-78$ \\
2 & $79-165$ \\
3 & $165-255$ \\
\hline
\end{tabular}

Tabel 3. Nilai Pixel Hasil Klasifikasi c2

\begin{tabular}{|c|c|}
\hline Klas & Nilai pixel \\
\hline 1 & $19-90$ \\
2 & $91-171$ \\
3 & $172-255$ \\
\hline
\end{tabular}

Tabel 4. Nilai Pixel Hasil Klasifikasi c3

\begin{tabular}{|c|c|}
\hline Klas & Nilai pixel \\
\hline 1 & $19-123$ \\
2 & $124-181$ \\
3 & $182-255$ \\
\hline
\end{tabular}

Gambar 5 menunjukkan hasil klasifikasi dari citra aproksimasi $\mathrm{c}_{3}$.

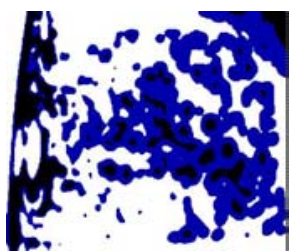

Gambar 5. Hasil Klasifikasi c3

\section{HASIL EXPERIMEN}

Sasaran dari penelitian ini adalah akan mendeteksi penyebaran tumor pada paru-paru. Karena dari hasil klasifikasi pada c0 dibanding dengan c1, c2 dan c3, terlihat adanya pengelompokan klas dengan nilai pixel yang berbeda. Hal ini menunjukkan bahwa dengan skala yang berbeda dapat diamati informasi pentebarab tumor lebih banyak. Setelah dilakukan transformasi dan klasifikasi maka proses terakhir berdasarkan nilai keabuan pada segmen-segmen dilakukan proses thresholding pada citra aproksimasi untuk mendapatkan ibyek yang diamati

Gambar 6a) adalah hasil thresholding dari citra c3 dengan nilai threshold 124-181 atau menunjukkan obyek klas 2. Sedang gambar 6b) menunjukkan obyek klas 1 dan gambar 6c) adalah gabungan obyek klas 1 dan klas 2 atau dengan nilai thresholding dari $19-181$.

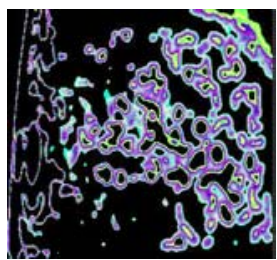

a)

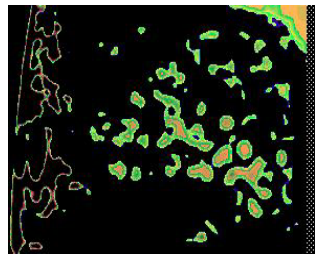

b)

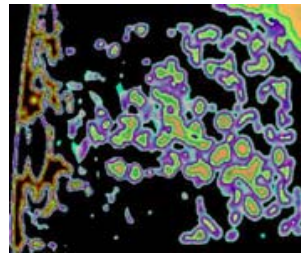

c)

Gambar 5. Hasil Threshold Citra c3 Pada klas 3 
Gambar 6 menunjukkan bahwa bulatan-bulatan hitam yang di identifikasi sebagai tunor pada citra asli ternyata tampak menjadi 2 klas bila dilihat pada level yang lebih tinggi yaitu $\mathrm{c} 1, \mathrm{c} 2$ dan $\mathrm{c} 3$.

\section{KESIMPULAN}

Dari hasil penelitian ini dapat ditarik kesimpulan bahwa :

- dalam deteksi obyek dibutuhkan pengamatan pada skala yang berbeda untuk dapat melihat penyebaran tumor yang sebelumnya tidak terlihat pada citra asli

- Pengamatan yang lebih detail dapat dilakukan dengan teknik thresholding untuk dapat melihat tepi dari suatu obyek.

\section{DAFTAR PUSTAKA}

[1] Bruzzone, D.F. Prieto, and S.B. Serpico, "A Neural-Statistical Approach to Multitemporal and Multisource Remote Sensing Image Classification", IEEE Transactions on Geoscience and Remote Sensing, Vol 37, pp.1350-1358, May 1999.

[2] Clark

[3] A. Murni, A.K. Jain, and J. Rais, A Framework for Multidate Multisensor Image Interpretation, Proceedings of International Geoscience and Remote Sensing Symposium (IGARSS'96), Lincoln, Nebraska, pp. 1851-1854, 1996.

[4] S. Sardy, Wihartini, and S. Jatno, The Area Change Detection on Synthetic Aperture Radar Images by using Wavelet Transform, Proceedings of the IASTED International Conference, Marbella, Spain, September 4-7, 2001.

[5] Wihartini and A. Murni, Informatiuon Fusion Based on Multiresolution and Multisensor SAR and Optical Sensor Segmented Images, Proceedings of the Map Asia Conference, 2005 